\title{
The Mechanical Behavior of Fiber Reinforced PP ECC Beams under Reverse Cyclic Loading
}

\author{
Yaw ChiaHwan and Han JianBo \\ Shenyang Architectural University, Hunnan East Road 9, Shenyang 110168, China \\ Correspondence should be addressed to Yaw ChiaHwan; 826125581@qq.com
}

Received 1 January 2014; Accepted 19 May 2014; Published 2 July 2014

Academic Editor: João Marciano Laredo dos Reis

Copyright ( 2014 Y. ChiaHwan and H. JianBo. This is an open access article distributed under the Creative Commons Attribution License, which permits unrestricted use, distribution, and reproduction in any medium, provided the original work is properly cited.

When a structure is hit by earthquake, tremendous amount of seismic energy is released and structure is subjected to reverse loads. The mechanical properties of FRP reinforced PP ECC beams and coupon RC beam under reverse cyclic load controlled by displacement are investigated. Curing ages, reinforcement ratio, and volume fraction of PP fiber are parameters under survey. It is shown that multiple saturated cracking occurred in PP ECC beam and no crushing appeared. The PP ECC can enhance strength and energy dissipation capacity which are important to evaluate the performance of structures subjected to reverse cyclic loading.

\section{Introduction}

During the last decade, significant efforts have been made to develop ECC which exhibits tough, strain-hardening behavior under tension in spite of low fiber volume fraction [1]. ECC is a kind of ultraductile fiber reinforced cement based composite which has metal-like features when loaded in tension. The uniaxial stress-strain curve shows a yield point followed by strain-hardening up to several percent of strain, resulting in a material ductility of at least two orders of magnitude higher than normal concrete or standard fiber reinforced concrete [2]. ECC provides crack width to below $100 \mu \mathrm{m}$ even when deformed to several percent of tensile strain.

An increasingly large database of mechanical (including tension, compression, shear, fatigue, and creep) and physical properties (including shrinkage and freeze-thaw durability) of ECC is now being established around the world [3,4], yet further research is needed for this novel composite. Anna [5] reported in Forbes self-healing phenomenon of PVA (Polyvinyl Alcohol) ECC and commented it as a novel composite which can bring revolution to civil engineering. Although Fisher and Li [6] have analyzed the failure mode of small scale connections and frames of PVA ECC, the tremendous cost has limited its application. The cost of PVA ECC is around 5 times that of ECC using PP (Polypropylene) fibers. Therefore it is necessary to utilize cheap Polypropylene fibers to produce ECC with extraordinary properties. Until now, research work on PP ECC was only reported by Yang and Li [7] in the world. In this study Polypropylene fibers with surface improved by copolymer technology are utilized to produce PP ECC. The chemical bond of interface is enhanced in the microscale. The mechanical properties of PP ECC members such as toughness, ductility, dissipated energy, and impact resistance are improved. Figure 1 shows the four point bending test of plain PP ECC. By substituting traditional concrete with PP ECC, both FRP reinforcement and ECC are deforming compatibly in the inelastic deformation regime. The defects of low dissipated energy of concrete structures can be avoided. In this paper, five FRP reinforced PP ECC beams and one coupon concrete beam under reverse cyclic loading are investigated. The effect of parameters, that is, volume fraction of PP fiber, curing age of specimen, and FRP reinforcement ratio on cracking pattern, dissipated energy and stiffness degradation is analyzed.

\section{Material Composition and Properties}

The PP ECC contains PP (Polypropylene) fibers, cement, fly-ash, fine aggregates (maximum grain size $0.25 \mathrm{~mm}$ ), and water. Viscosity modification agent (VMA) and high-range superplasticizer (SP) are used to enhance the fresh properties 

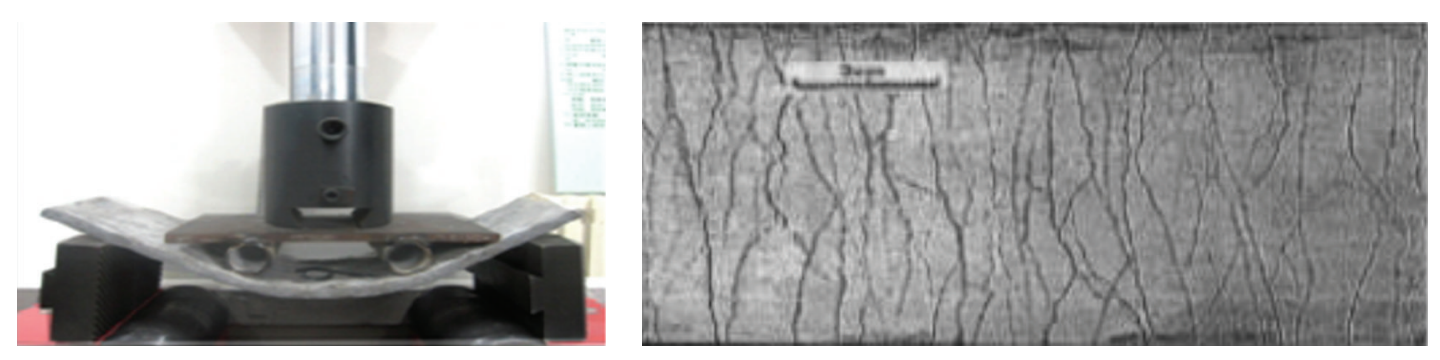

FIGURE 1: Four point bending test of plain PP ECC and multiple saturated cracking.

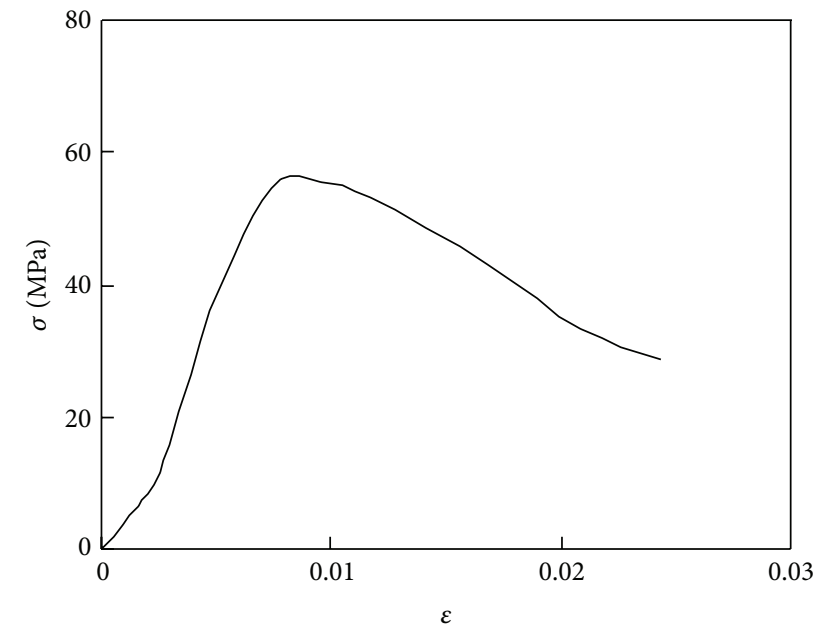

(a) Stress-strain curve of PP ECC under compression

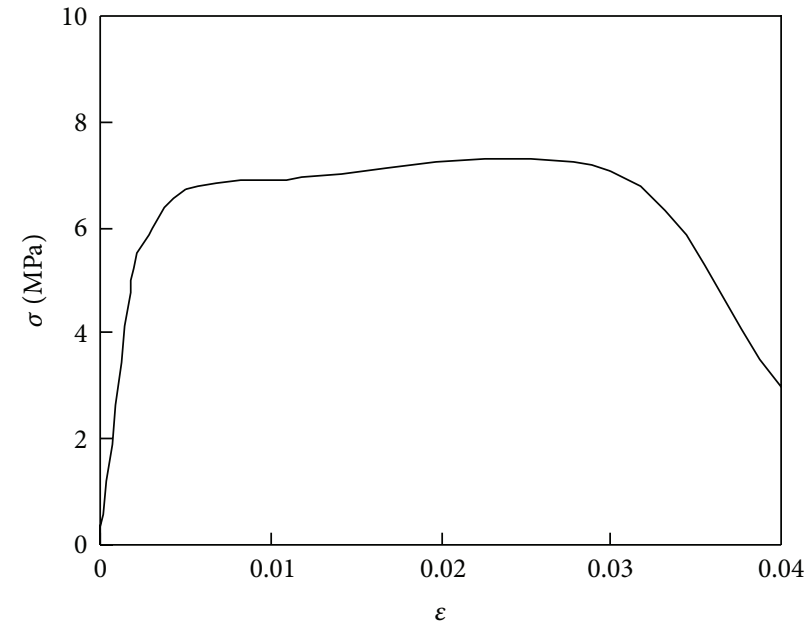

(b) Stress-strain curve of PP ECC under tension

FIGURE 2: Stress-strain curves of PP ECC.
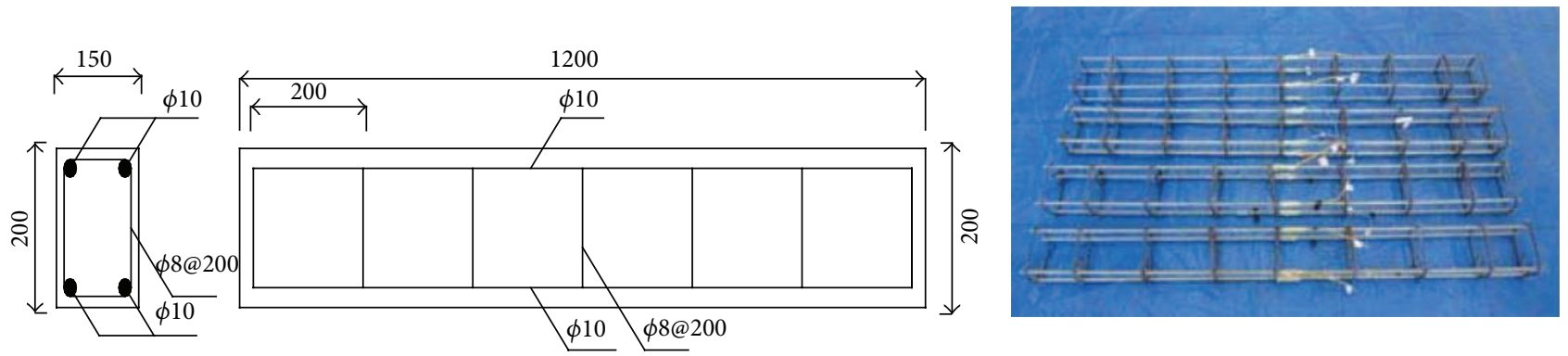

Figure 3: Dimensions and reinforcement details of specimens.
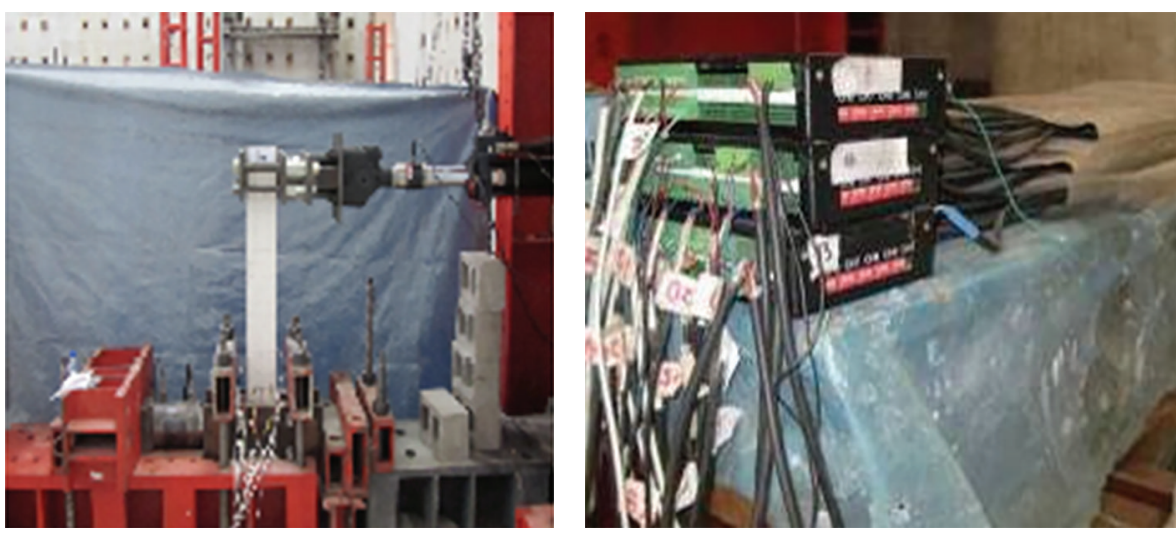

FIGURE 4: Setup of test and data acquisition board. 
TABle 1: Parameters of specimen.

\begin{tabular}{lccccc}
\hline Specimen number & $\begin{array}{c}\text { Volume fraction of fiber } \\
(\%)\end{array}$ & $\begin{array}{c}\text { Bar diameter } \\
\varphi(\mathrm{mm})\end{array}$ & $\begin{array}{c}\text { Reinforcement ratio } \\
\rho(\%)\end{array}$ & $\begin{array}{c}f_{\text {cu }} \\
(\mathrm{MPa})\end{array}$ & $\begin{array}{c}\text { Curing age } \\
(\mathrm{days})\end{array}$ \\
\hline B1 & 1.5 & 8 & 0.76 & 56 & 60 \\
B2 & 1.5 & 10 & 1.20 & 56 & 60 \\
B3 & 2.0 & 10 & 1.20 & 40 & 50 \\
B4 & 1.5 & 10 & 1.20 & 56 & 30 \\
B5 & 1.5 & 12 & 1.72 & 56 \\
B6 & 0 & 10 & 1.20 & 40 & 30 \\
\hline
\end{tabular}

TABLE 2: Property of FRP bars.

\begin{tabular}{lccccc}
\hline Model & Density $\left(\mathrm{g} / \mathrm{cm}^{3}\right)$ & Section area $\left(\mathrm{cm}^{2}\right)$ & Yield strength $(\mathrm{MPa})$ & Tensile modulus $(\mathrm{GPa})$ & Debonding strength $(\mathrm{MPa})$ \\
\hline FRP-8 & 3.16 & 0.56 & 707.5 & 64.0 & $>15 \mathrm{MPa}$ \\
FRP-10 & 3.6 & 0.91 & 1027.5 & 89.0 & $>12 \mathrm{Mpa}$ \\
FRP-12 & 3.21 & 1.31 & 836.6 & 65.3 & $>10 \mathrm{MPa}$ \\
\hline
\end{tabular}

of the mixture. Concrete uses coarse aggregates (maximum grain size $10 \mathrm{~mm}$ ), cement, water, and high-range SP.

When producing PP ECC, the sand and cement are mixed dryly first approximately for 30-60 seconds until the mixture becomes homogeneous. Then water, fly ash, SP, and VMA are added orderly. SP and VMA are used only when the mixer cannot mix further. At the end the fibers are added but the mixture can be mixed for only $30 \mathrm{~s}$, otherwise it will be very clumpy. Stress-strain curves of PP ECC from this composition under uniaxial tension and compression were demonstrated in Figure 2.

In this paper, a selection of five PP ECC and 1 concrete beams involving FRP bars as reinforcing material is presented. FRP reinforcing bars with diameters of 8,10 , and $12 \mathrm{~mm}$ are arranged symmetrically in the beams of cross section of $150 \times 200 \mathrm{~mm}$ as longitudinal reinforcement. The parameters under survey and specimen number are listed in Table 1. The parameters include volume fraction of PP fiber $(1.5 \%-2.0 \%)$, curing age of specimen (30 and 60 days), and FRP reinforcement ratio.

FRP bars of 8,10 , and $12 \mathrm{~mm}$ diameter, respectively, with characteristic yield strengths of $707.5 \mathrm{MPa}, 1027.5 \mathrm{MPa}$, and $836.6 \mathrm{MPa}$ were used as conventional reinforcement satisfying the requirement of design code for minimum reinforcement. The property of FRP bars is shown in Table 2. Flexural failure of the beam was ensured by providing necessary shear reinforcement (stirrup of $6 \mathrm{~mm}$ diameter with $200 \mathrm{~mm}$ space). The geometry of the test specimen and reinforcement details are shown in Figure 3.

\section{Test Specimen}

The behavior of FRP reinforced PP ECC beams was experimentally investigated and compared to FRP reinforced concrete beam. All the flexural members were of cross section of $150 \times 200 \mathrm{~mm}$ and a clear span of $1.2 \mathrm{~m}$. A clear protection cover of $25 \mathrm{~mm}$ was provided in all specimens

In this study, reinforced PP ECC beams with different fiber volume fractions, bar diameters, and curing ages are named as B1 to B5. A total of 5 PP ECC beams and 1 concrete beam were cast with ECC mix proportions given in Table 3. The coupon specimen of reinforced concrete beam is named as B6.

\section{Experimental Setup and Testing Procedure}

Cyclic tests were performed using MTS Hydroplus Machine with maximum capacity of $100 \mathrm{kN}$ in static loading and $80 \mathrm{kN}$ in dynamic loading. Schematic diagram of the experimental setup is shown in Figure 4. This loading configuration was chosen to promote a flexural deformation mode in all specimens. In this way, the effect of PP ECC properties on the expected plastic hinge region can be learned.

Lateral loading was applied through a MTS actuator according to a displacement-controlled reverse cyclic loading sequence. The loading rate was kept at $0.2 \mathrm{~mm} / \mathrm{second}$ for imposed deflection. For each cycle, the imposed deflection increased by $2 \mathrm{~mm}$ or $4 \mathrm{~mm}$ before or after it reached $24 \mathrm{~mm}$, respectively. The experiment stopped once the applied load dropped to $85 \%$ of the ultimate load.

In PP ECC specimen B1 with transverse reinforcement (Figure 5), flexural cracking formed during the initial loading cycles and extended up to $720 \mathrm{~mm}$ specimen height at $28 \mathrm{~mm}$ drift. The debonding between FRP bars and ECC started to occur. The approximate crack spacing was $40 \mathrm{~mm}$ and maximum crack width was below $0.1 \mathrm{~mm}$. Then the number of flexural cracks increased significantly with crack formation up to $950 \mathrm{~mm}$ specimen height. At this loading stage, neither localization nor bond splitting of flexural cracks was observed. The average crack spacing reduced to $20 \mathrm{~mm}$ with a maximum crack opening of $0.2 \mathrm{~mm}$ at the cantilever base. However, few minor shear cracks formed in the midsection of the cantilever. At $32 \mathrm{~mm}$ drift, the number of flexural cracks stabilized and cracking localized at the cantilever base; shear failure was not observed. Additional cracks extended to $1080 \mathrm{~mm}$ height at a 45 degree angle and interconnected cracks which already existed. Beyond $48 \mathrm{~mm}$ drift, a tendency 
TABLE 3: Mix proportions of ECC.

\begin{tabular}{lcccccc}
\hline Cement & Silica sand & Fly ash & Water & Superplasticizer & Fiber volume fraction (\%) & VMA \\
\hline 1.0 & 0.8 & 1.2 & 0.66 & $0.013 \%$ & 2.0 & $0.03 \%$ \\
\hline
\end{tabular}

TABle 4: Degeneration factor of load bearing capacity.

\begin{tabular}{|c|c|c|c|c|c|c|c|c|}
\hline \multirow{2}{*}{ Degradation } & \multicolumn{8}{|c|}{ Displacement } \\
\hline & $24 \mathrm{~mm}$ & $28 \mathrm{~mm}$ & $32 \mathrm{~mm}$ & $36 \mathrm{~mm}$ & $40 \mathrm{~mm}$ & $44 \mathrm{~mm}$ & $48 \mathrm{~mm}$ & $52 \mathrm{~mm}$ \\
\hline \multicolumn{9}{|l|}{ Specimen } \\
\hline B1 & 0.91 & 0.91 & 0.96 & 0.93 & 0.9 & 0.87 & 0.89 & 0.91 \\
\hline B2 & 0.9 & 0.91 & 0.92 & 0.8 & 0.96 & 0.9 & 0.78 & 0.8 \\
\hline B3 & 0.9 & 0.92 & 0.88 & 0.82 & 0.85 & 0.91 & 0.9 & 0.9 \\
\hline B4 & 0.93 & 0.92 & 0.91 & 0.95 & 0.92 & 0.92 & 0.9 & 0.9 \\
\hline B5 & 0.92 & 0.93 & 0.93 & 0.92 & 0.9 & 0.91 & 0.92 & 0.93 \\
\hline
\end{tabular}
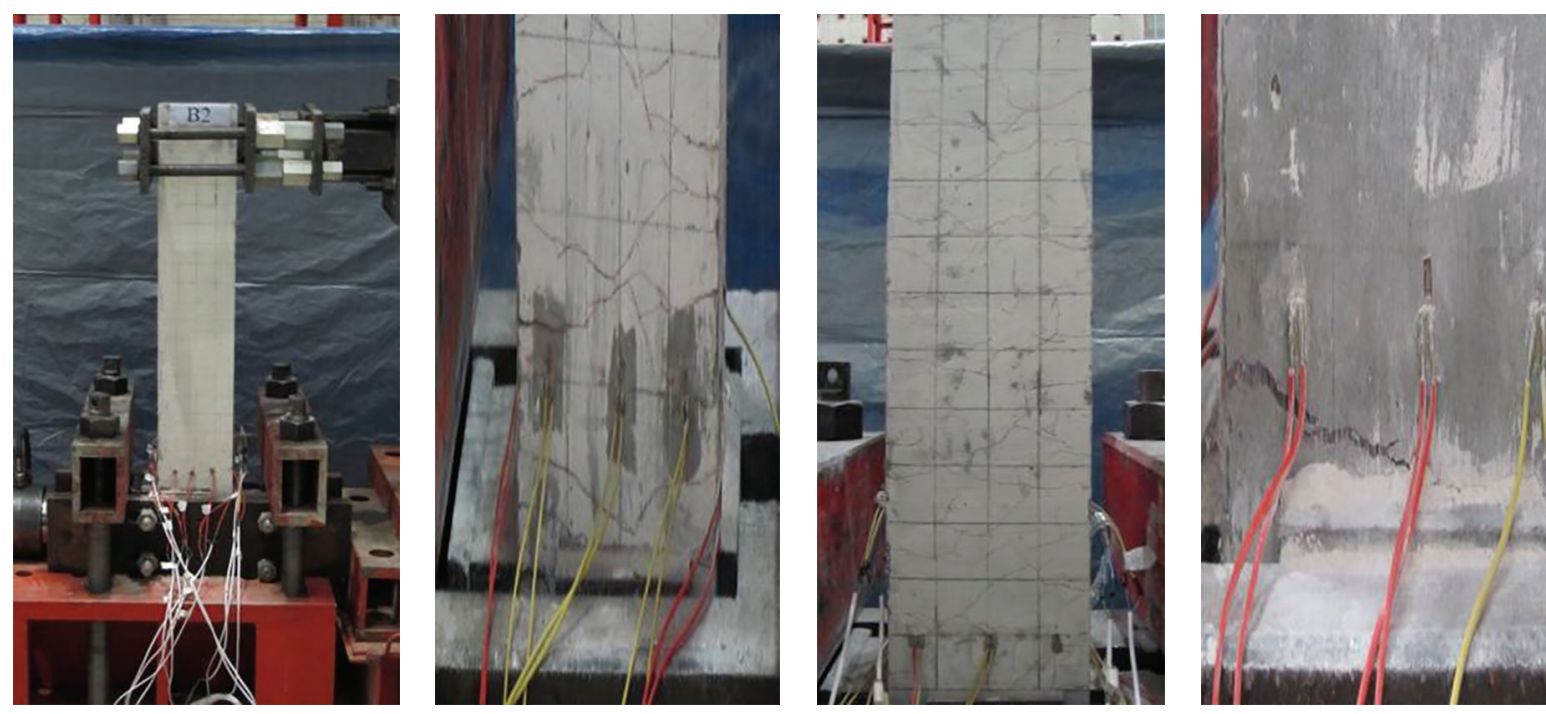

FIgURE 5: Failure modes of PP ECC specimen.
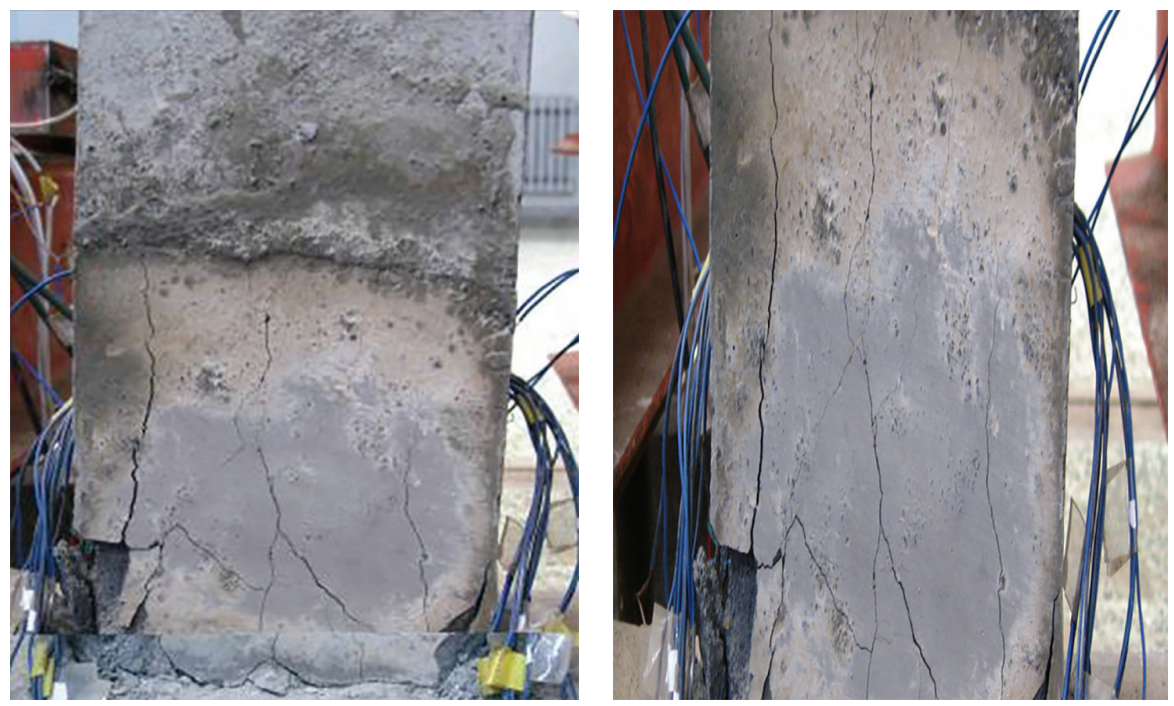

FIgURE 6: Failure modes of concrete specimen. 


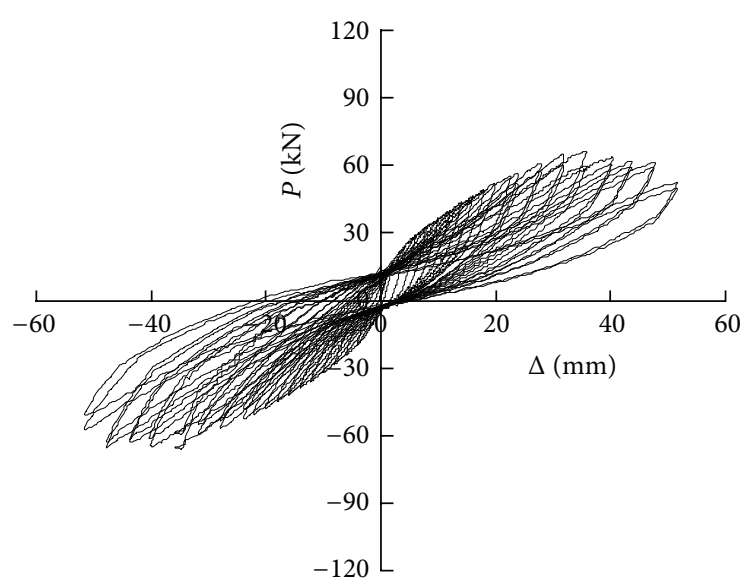

(a) B1

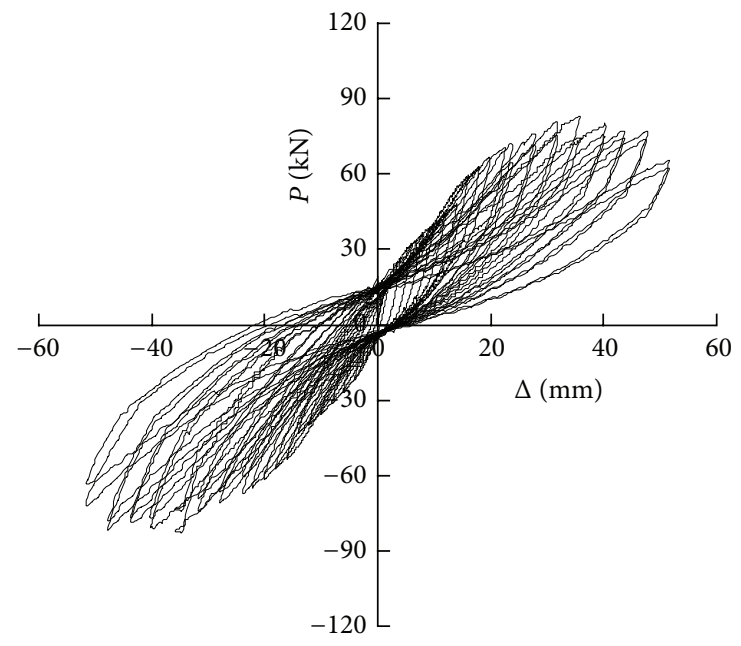

(c) $\mathrm{B} 3$

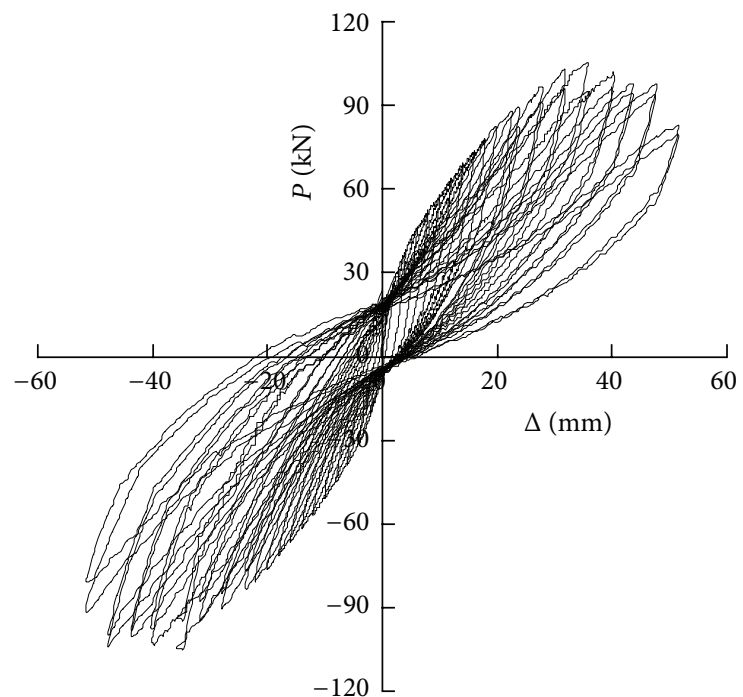

(e) B5

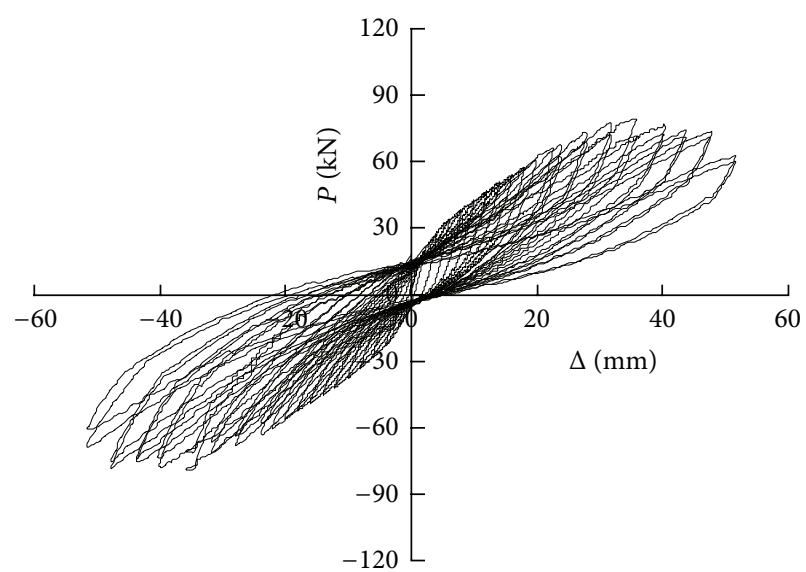

(b) B2

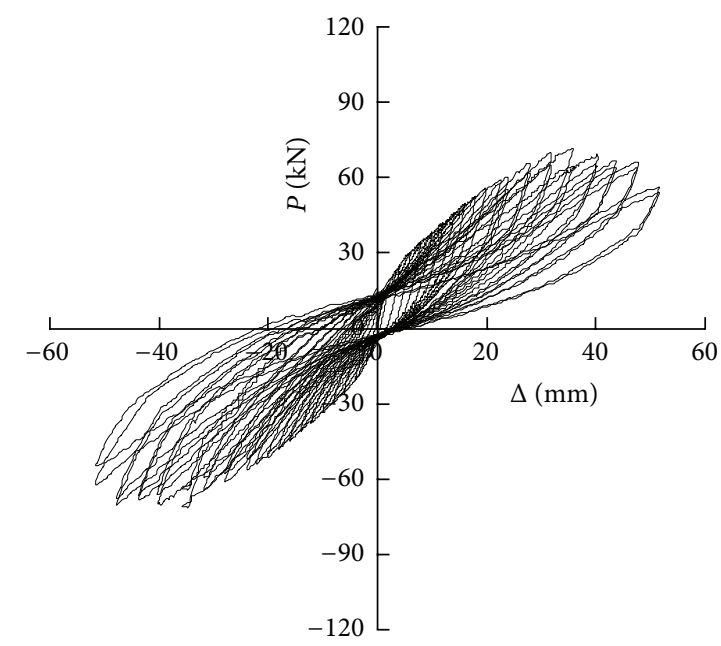

(d) B4

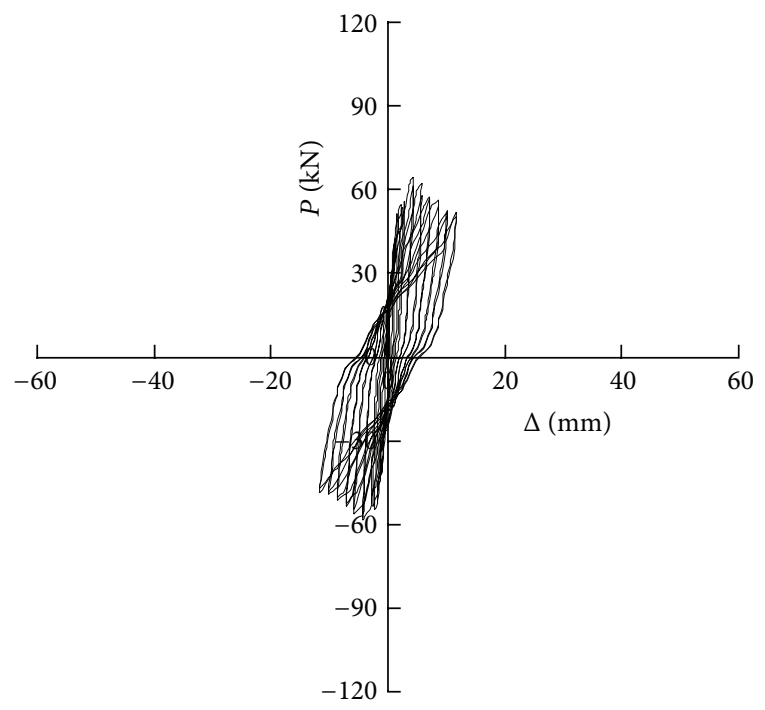

(f) $\mathrm{B} 6$

FIgURE 7: $P-\Delta$ hysteresis curve of FRP reinforced PP ECC and concrete specimen. 


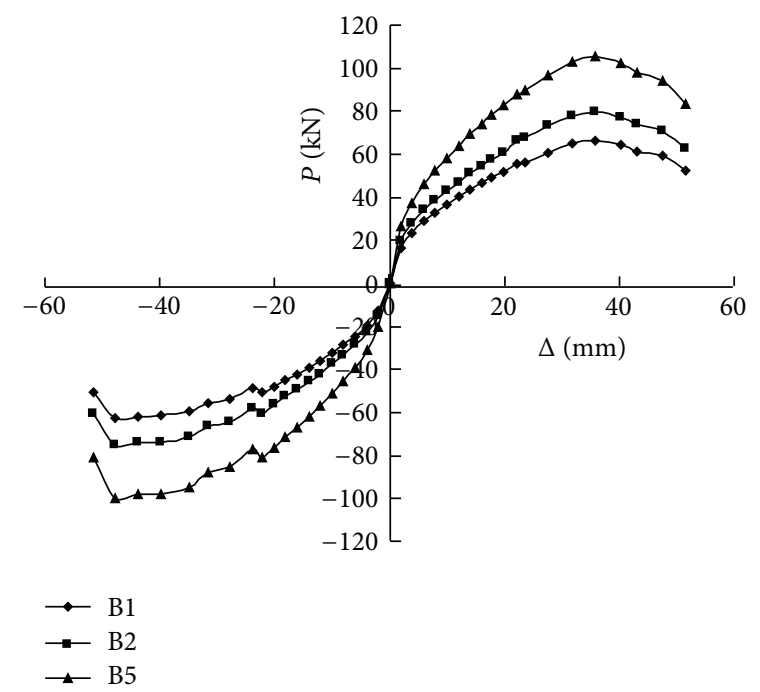

(a)

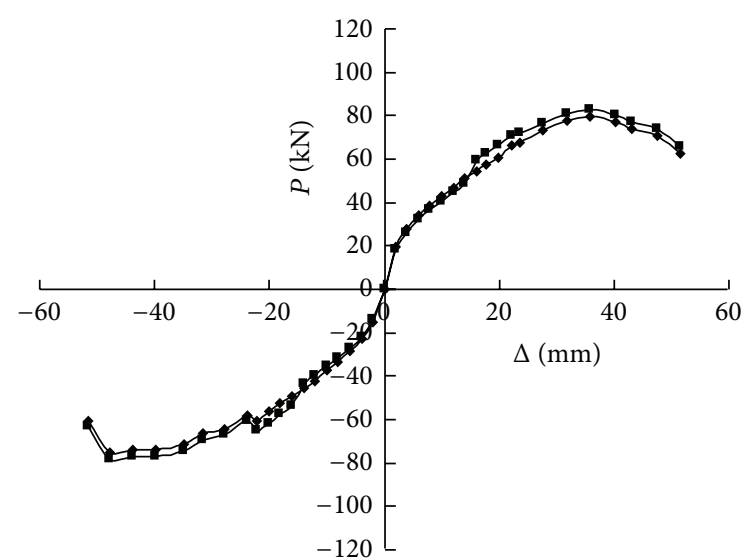

$\rightarrow \mathrm{B} 2$

$-\mathrm{B} 3$

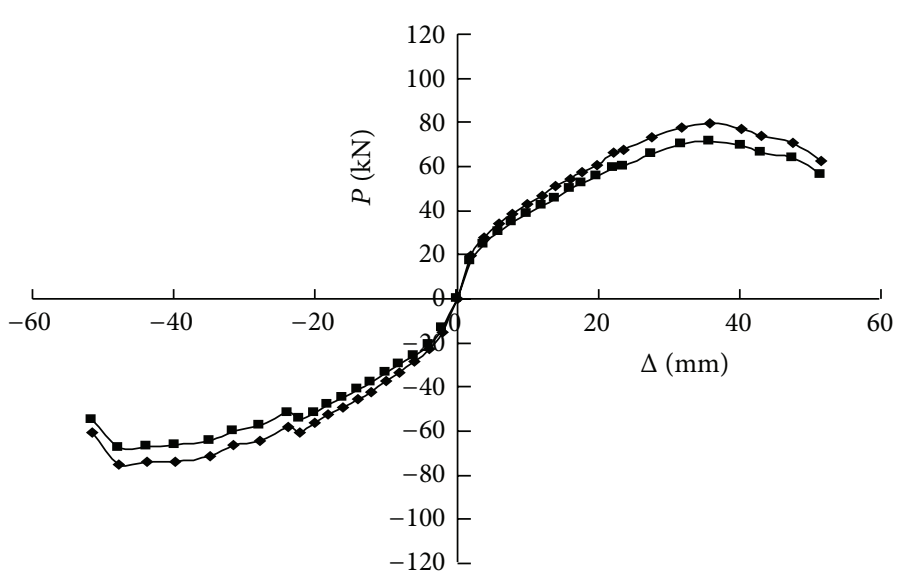

$\rightarrow \mathrm{B} 2$

(b)

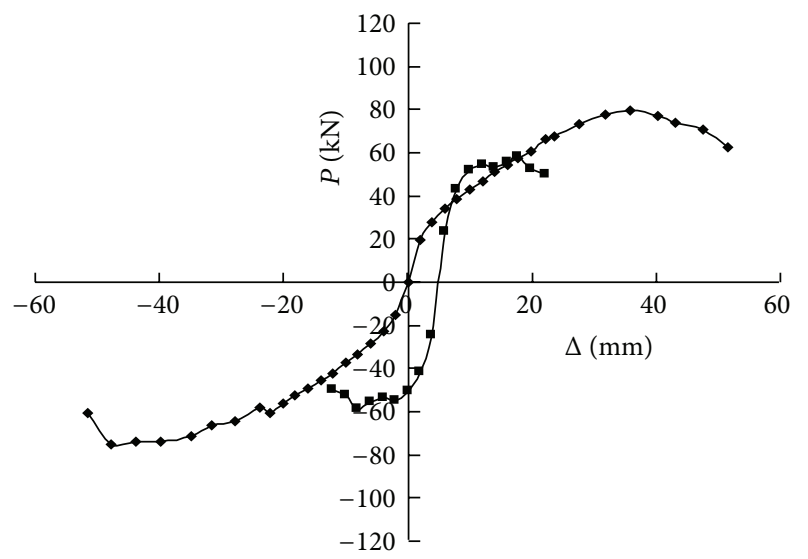

$\rightarrow \mathrm{B} 2$

$\rightarrow \mathrm{B} 6$

(c)

(d)

FIGURE 8: Influences of different parameters on $P-\Delta$ hysteresis curve.

of rotational sliding and grinding between the foundation and cantilever section along with interconnected flexural crack plane occurred, while only minor crushing of ECC observed.

The deformation behavior of Specimen B2-B5 was very similar to that of specimen B1. A concentration of flexural cracking was observed at the cantilever base and no obvious crushing of ECC occurred. All the crack width remained below $0.3 \mathrm{~mm}$. However, the distribution of flexural cracking was more uniform with a larger average spacing and less significant shear crack formation. As the load surpassed the bearing capacity of the specimen, the width of the crack increased until a horizontal main crack appeared in the tension face near the cantilever base. Simultaneously, sound of the PP fibers being pulled out and ruptured from the matrix can be clearly heard. Upon unloading, all the crack width returned to the state of initial loading cycles.

In beam B6 of reinforced concrete (Figure 6), no multiple cracking was observed and flexural cracking initiated at the cantilever base in the first loading cycle. Individual cracks propagated from the tension side and formed connecting crack paths upon reverse load. At deflection of $2 \mathrm{~mm}$, only flexural cracking was observed at an approximate spacing of $100 \mathrm{~mm}$. The maximum crack width of $1 \mathrm{~mm}$ was found on the tension face near the base of the specimen.

As the load increased, the number of flexural cracks slightly increased. Also the cracks extended to $840 \mathrm{~mm}$ height of the specimen with a maximum crack opening of $2 \mathrm{~mm}$ at the cantilever base. Additional cracks initiat- 

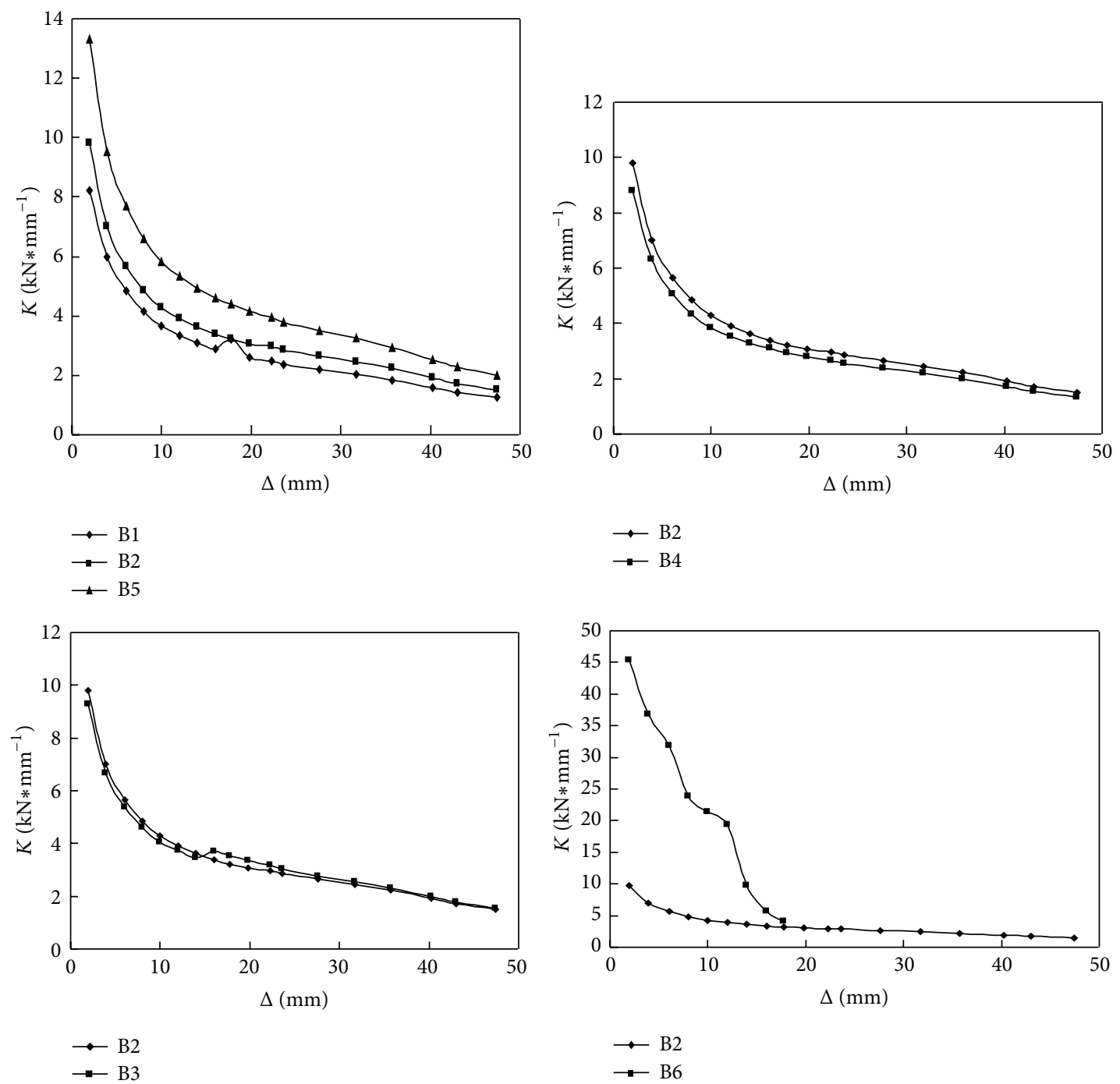

FIGURE 9: Influences of parameters on stiffness.

ing at the intersection of existing flexural cracks or longitudinal reinforcement became apparent at deflection of $4 \mathrm{~mm}$. Then the cracks propagated along the FRP reinforcement under the influence of compressive stress in the reverse half-cycle. Due to further crushing of concrete in the initial half-cycle at deflection of $10 \mathrm{~mm}$, the longitudinal FRP reinforcement experienced excessive compressive strain and ruptured by tension in the reverse half-cycle (Figure 6).

Spalling of concrete cover is a common problem with structural element subjected to reverse cyclic loading, because each element comes alternatively in compression and tension. In this experiment, the spalling of PP ECC cover did not occur. However the spalling of concrete cover was severe. It is due to the fact that before fibers break or slip from the matrix, they always hold the cementitious matrix tight by bridging the cracks. Reduction in the spalling of concrete by the use of PP fibers in structural member subjected to reverse cyclic loading can lead to less maintenance and rehabilitation cost after earthquake.

\section{Hysteretic Response}

Structures are expected to enter elastoplastic range under dynamic loading or strong earthquake, so hysteresis curve is useful for analysis of seismic elastoplastic response. Hysteresis loops $(P-\Delta)$ are load-displacement relationships of structures under cyclic loading. Figure 7 shows the lateral force $(P)$ versus top displacement $(\Delta)$ relationship for beams B1 to B6. For all specimens, maximum load during each cycle of imposed deflection was recorded.

The hysteretic curve is linear at the initial loading cycle for PP ECC beams B1-B5. At 60\%-70\% load bearing capacity, the hysteretic curves behaved nonlinearly as the specimens entered elastoplastic stage. When the drift $\Delta$ equals $30 \mathrm{~mm}$, the hysteretic loop changed from spindle to reversed $S$ shape. After that the loops began to flatten out, showing that less force was required to maintain the same displacement in the beam. Throughout the whole test, the loops became fatter and fatter as the load increased. The enlarged hysteretic loops 

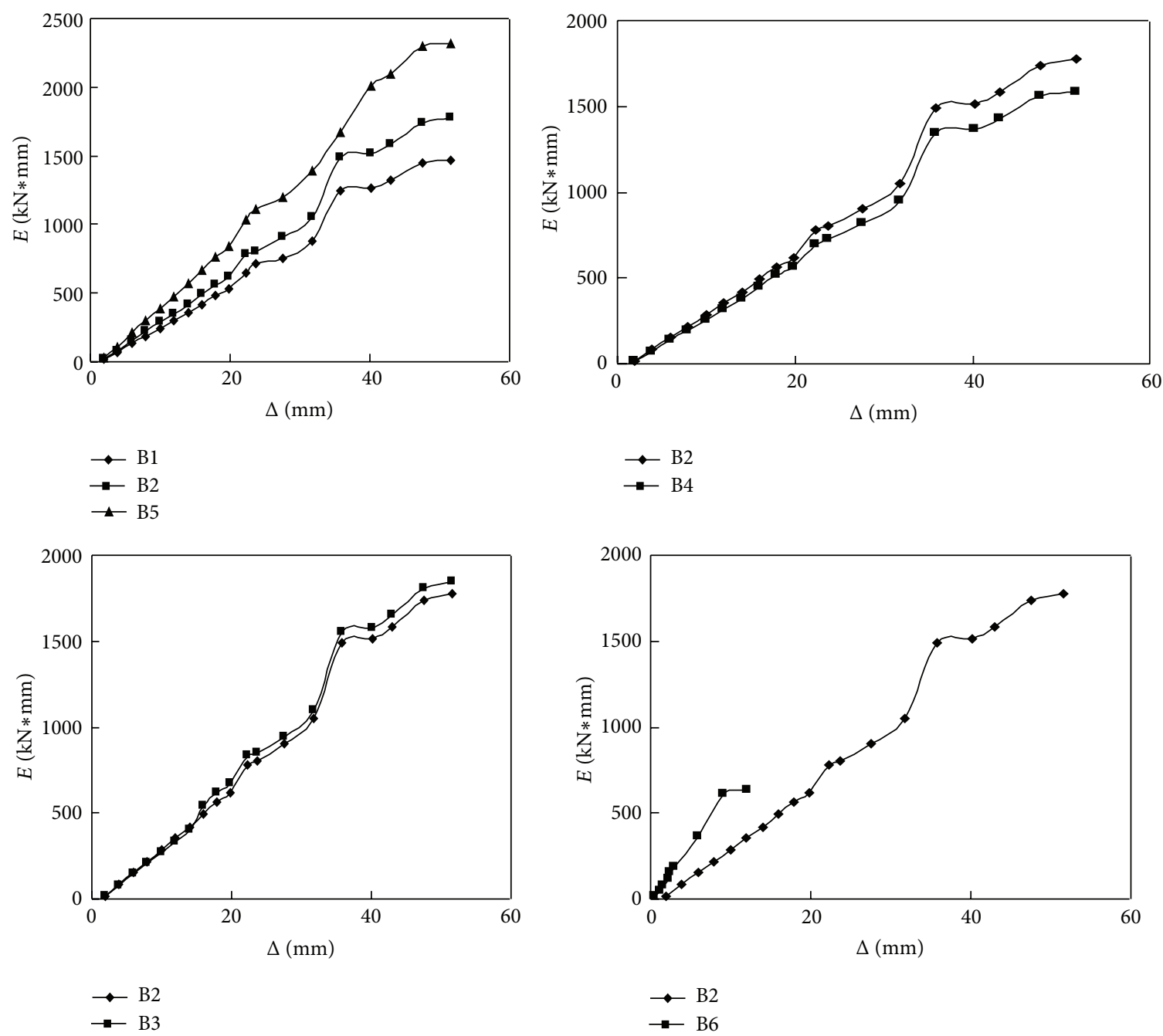

FIGURE 10: Influences of parameters on dissipated energy.

indicated an increase in energy dissipation. For reinforced concrete beam B6, no obvious pinching phenomenon can be observed in the hysteretic loop. As the top displacement $\Delta$ reached $10 \mathrm{~mm}$, almost all the concrete protection cover near the base are crushed.

\section{Skeleton Curve}

The influence of reinforcement ratio, curing age, and volume fraction of PP fiber on skeleton curve is shown in Figure 8. It is found in Figure 8(a) that the load bearing capacity of PP ECC beams increased with higher reinforcement ratio. In Figure 8(b), it is shown that the load bearing capacity of beam B2 is higher than B3; however the ductility is obviously lower. Therefore it can be stated that the longer curing age of PP ECC, the higher load bearing capacity and lower ductility. It is observed in Figure 8(c) that there is no much difference for the skeleton curves of specimens B2 and B4. So the different volume fraction of fibers $1.5 \%$ and $2 \%$ does not have much effect on the ductility and load bearing capacity of reinforced
PP ECC beam. However, the shapes of skeleton curves of specimens B2 and B6 are different. The top displacement of PP ECC beam B2 especially is almost 3 times that of concrete beam B6. Therefore, it is obvious that the ductility of PP ECC is far better than concrete.

\section{Degradation of Load Bearing Capacity and Stiffness}

The factor of load bearing capacity degradation is defined as $\lambda=P_{2 \max } / P_{1 \text { max }}$, namely, the ratio of peak load value at 2 nd cycle to that of 1 st cycle at the same drift level. The factor of load bearing capacity degradation of each hysteresis curve is shown in Table 4 . The difference for $\lambda$ of the five PP ECC specimens is not obvious, with $8 \%$ reduction at most. So the parameters including volume fraction of PP fiber $(1.5 \%-2.0 \%)$, curing age of specimen (30 and 60 days), and FRP reinforcement ratio do not have much effect on $\lambda$. This is mainly due to the fact that no coarse aggregates are utilized in 
PP ECC and more fibers are pulled out and ruptured during the 2nd loading cycle.

Stiffness of the beam under reverse cyclic load decreases as the load cycle number increases. Factor of stiffness degradation can be defined as $K=\sum P_{i} / \sum \Delta_{i}$, namely, the ratio of the sum of peak load value to the sum of top displacement during every adjacent two cycles of the same drift. The relationship of top displacement $\Delta$ and factor of stiffness degradation $K$ is shown in Figure 9.

It is obvious that lower reinforcement ratio corresponds to lower stiffness of the beams. The degradation of PP ECC and concrete beams started at $10 \mathrm{~mm}$ and $18 \mathrm{~mm}$ drift, respectively. However the volume fraction of PP fiber does not make much difference to the stiffness degradation. Before yielding, the stiffness degradation of the PP ECC beam is almost the same at curing ages of 30 and 60 days. After yielding, the stiffness degradation of PP ECC beams with 30 days curing age is more obvious than that of 60 days. It is calculated that the original stiffness of concrete beam is around 5 times that of PP ECC beams. However the degradation of concrete is more serious at later stage.

\section{Cumulative Dissipated Energy}

Energy dissipation in a loading cycle is the area that hysteresis loop encloses in the corresponding load-deflection curve. The cumulative dissipated energy $E$ is then determined by adding the energy dissipated in consecutive loops throughout the test (Figure 10). Overall speaking, the value of dissipated energy is greater for specimens with FRP bars of bigger diameter. The value of dissipated energy for specimens with different volume fractions of fiber (1.5\% and $2 \%$ ) does not have much difference. The value of dissipated energy for specimen of longer curing age (60 days) is greater than that of shorter curing age (30 days). The dissipated energy for concrete beam is more than that of PP ECC specimen before the drift $\Delta$ reached $10 \mathrm{~mm}$. The drifts $\Delta$ of beams B2 and B6 at load bearing capacity are $35.8 \mathrm{~mm}$ and $4.3 \mathrm{~mm}$, respectively. The total dissipated energy of PP ECC beam is around 3.2 times of coupon beam.

\section{Conclusions}

Through visual observations, it was found that reduction of flexural crack width in PP ECC beams occurred. Moreover, No spalling or crushing of ECC cover was observed. The top displacement $\Delta$ of PP ECC beams upon yielding is around 3 times that of concrete beam. The bigger the diameter of FRP bars, the bigger the load bearing capacity and the energy dissipation capacity of PP ECC beam. The difference of volume fraction of fiber does not have much effect on the ductility, stiffness degradation of reinforced PP ECC beam. However, the longer the curing age (60 days) of PP ECC, the higher the load bearing capacity and the lower the ductility. The curing age has limited effect on the stiffness degradation and dissipated energy. The dissipated energy of PP ECC beam is 2.9 times that of coupon concrete beam. Moreover, less damage is observed in PP ECC since fibers always try to hold the cementitious matrix by crack bridging.
During an earthquake, the structures are always required to withstand seismic forces without significant reduction in the strength and serviceability limit state. After the earthquake, rehabilitation and maintenance cost should be as low as possible. It is obvious that FRP reinforced PP ECC can improve load bearing capacity and energy dissipation capacity of the beams. Therefore, PP ECC is promising for future structures to behave more effectively against seismic action.

\section{Conflict of Interests}

The authors declare that there is no conflict of interests regarding the publication of this paper.

\section{References}

[1] S. Wang, Micromechanics based matrix design for engineered cementitious composites [Ph.D. thesis], University of Michigan, Ann Arbor, Mich, USA, 2005.

[2] M. Maalej, S. T. Quek, and J. Zhang, "Behavior of hybridfiber engineered cementitious composites subjected to dynamic tensile loading and projectile impact," Journal of Materials in Civil Engineering, vol. 17, no. 2, pp. 143-152, 2005.

[3] E. H. Yang, Designing added functions in engineered cementitious composites [Ph.D. thesis], University of Michigan, Ann Arbor, Mich, USA, 2008.

[4] E. H. Yang, S. Wang, Y. Yang, and V. C. Li, "Fiber-bridging constitutive law of engineered cementitious composites," Journal of Advanced Concrete Technology, vol. 6, no. 1, pp. 181-193, 2008.

[5] V. B. Anna, "Self-healing concrete," Forbes, vol. 2, pp. 46-47, 2009.

[6] G. Fischer and V. C. Li, "Effect of matrix ductility on deformation behavior of steel Reinforced ECC flexural members under reversed cyclic loading conditions," ACI Structural Journal, vol. 99, no. 6, pp. 781-790, 2002.

[7] E. H. Yang and V. C. Li, "Strain-hardening fiber cement optimization and component tailoring by means of a micromechanical model," Construction and Building Materials, vol. 24, no. 2, pp. 130-139, 2010. 

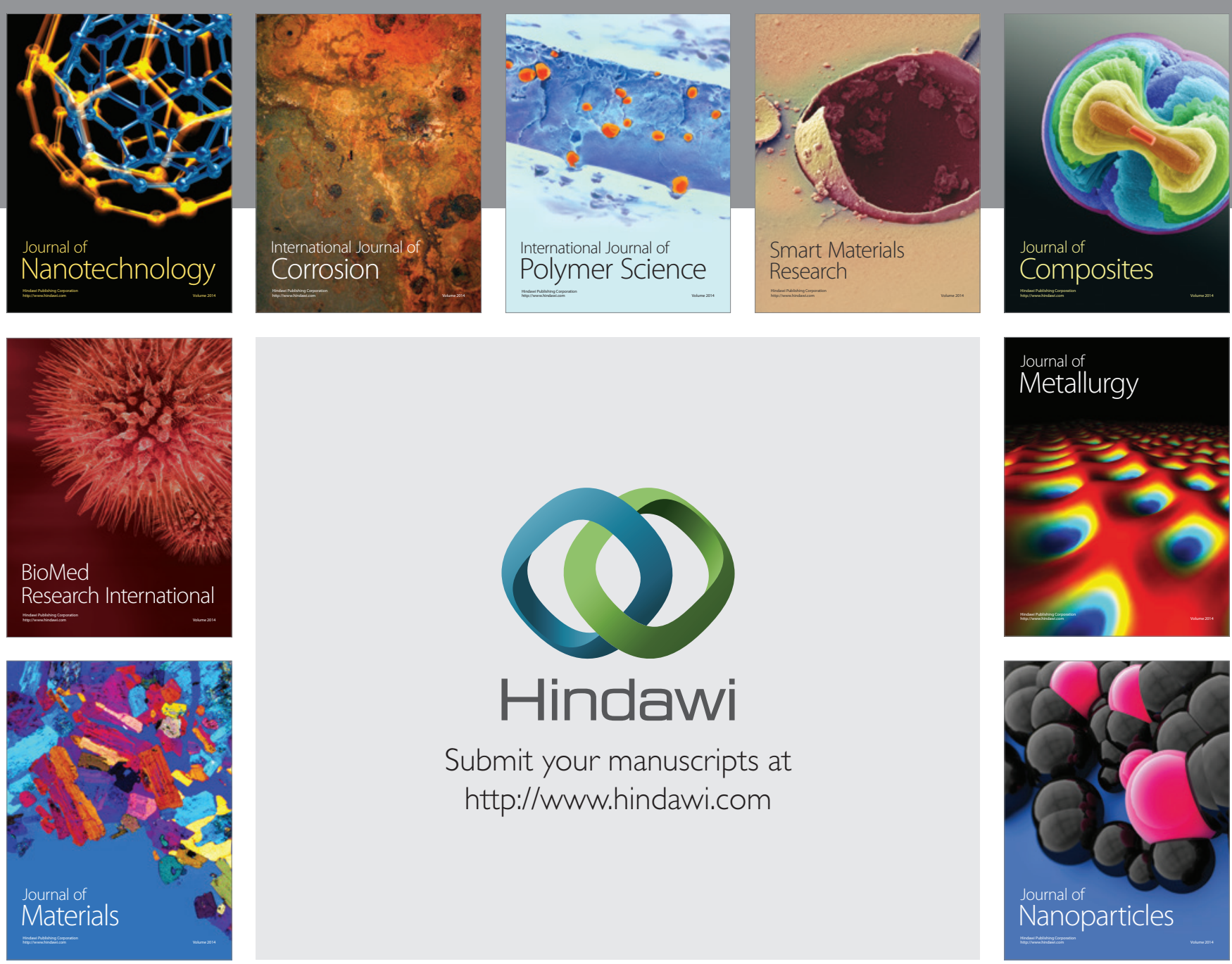

Submit your manuscripts at http://www.hindawi.com
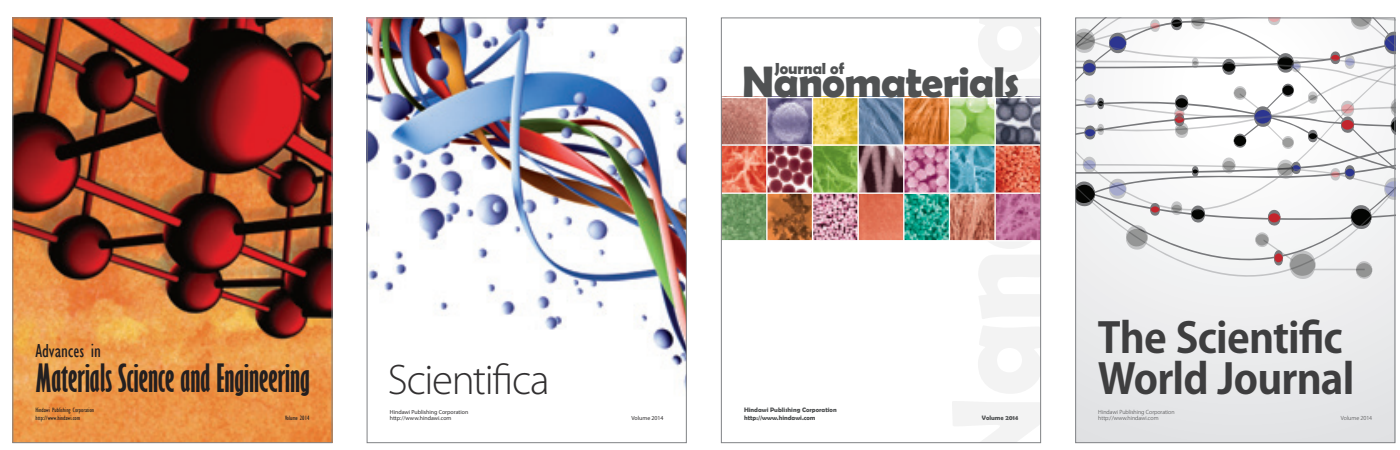

\section{The Scientific World Journal}
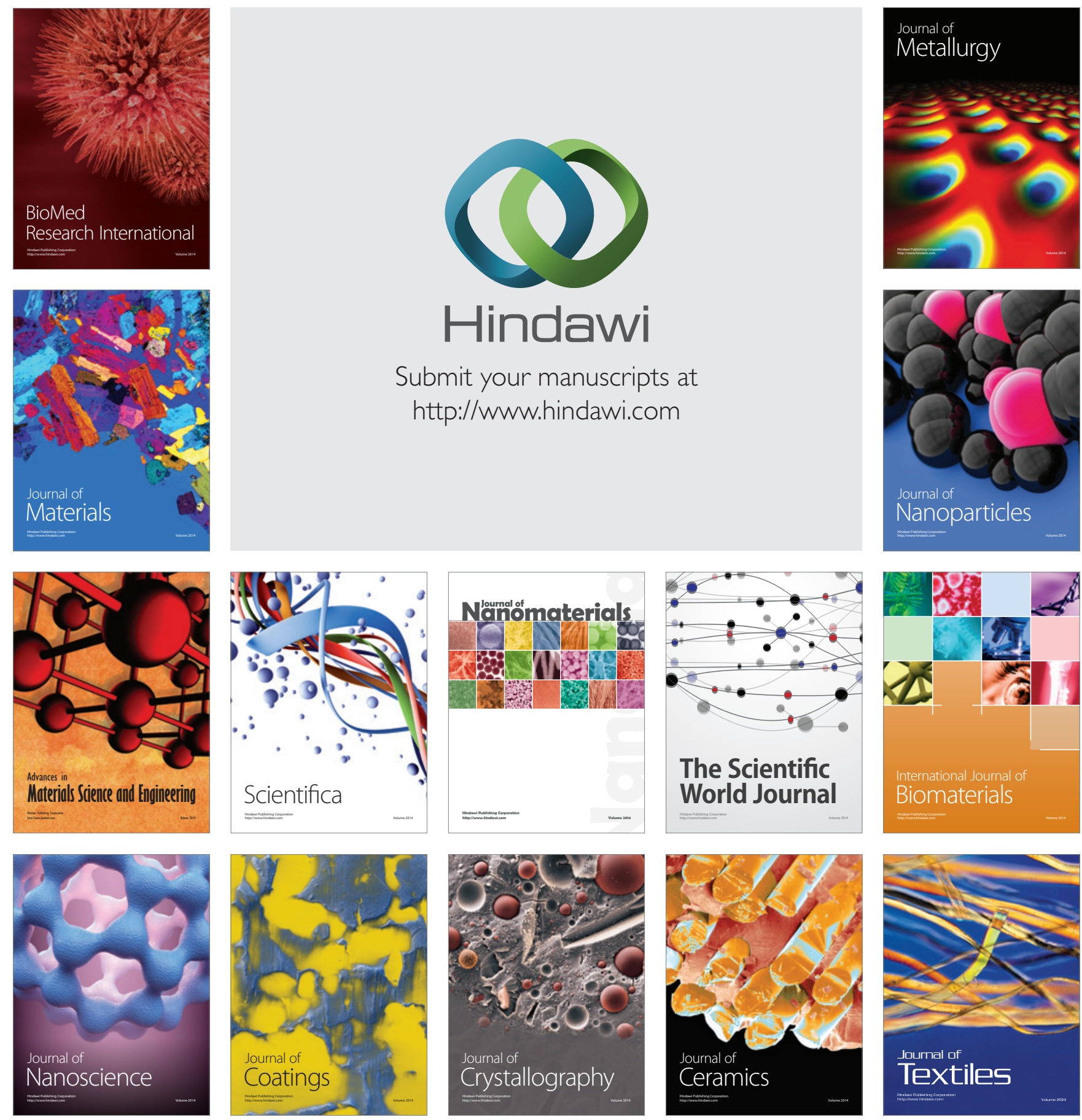